\title{
Mental Strength among MSU Athletes in Sports Performance
}

\author{
Pagdato, V. Jonathan ${ }^{\# 1}$, Adlawan, A. Hendely*2 ${ }^{2}$, Fadare, A. Stephen ${ }^{\# 3}$ \\ ${ }^{1,2,3}$ College of Sport Physical Education and Recreation, Mindanao State University (Main) Marawi, \\ Philippines.
}

\begin{abstract}
This study used a descriptive-correlation type of research to assess the mental toughness among MSU Marawi athletes in sports performance in terms of level of competition and rank among male and female varsity athletes in the events of Athletics, Badminton, Basketball, Chess, Sepak Takraw, and Soccer. A total of 83 varsity athletes (16 females and 67 males) of the MSU in Marawi City were the respondents of the study. Data was gathered using the Mental Toughness Questionnaire made by Allan Goldberg (1998). The findings revealed that the playing experience showed significant relationship with the level of participation. It was concluded that the department of Athletics should give more emphasis on training and allow participation of $M S U$ varsity in different competition or tournament in order to improve their talent and skills in various sports that they engaged, in order to manage competitive stress and to enhance their mental capability to handle those pressures, stressors and problems during the competition which contributes to their performance enhancement. To also, encourage more participation of the MSU varsity athletes, particularly newbie regardless of age, gender, and skills status.
\end{abstract}

Keywords: Mental Toughness, Sport Performance, varsity Athletes.

\section{INTRODUCTION}

Sports psychology is a science in which psychological principles are applied in a sports or exercise setting. These principles are often used to enhance performance and understand how participation in sport, training, exercise, and physical activity affects psychological development, health, and wellbeing in all stages of life (Cox, 2002).

According to Alderma (1974), sports psychology studies a person's behaviour in sport. It deals with increasing performance by managing emotions and minimizing the psychological effects of injury and poor performance. According to the American Psychological Association, sports psychology involves the study of the psychological effects involved with involvement and performance in sports, exercise, and other forms of physical activity (APA, 2012).

Many athletes and coaches are turning to sport psychology for a competitive advantage, enrolling in psychological training programs to learn how to handle competitive stress, control attention, build confidence, and improve communication and team harmony, among other things (Williams, 2001).

All sports participants fall to mistakes and mental letdowns. The emotional component always overshadows the technical aspects of performance. The surpasses can be avoided when sports participants are equally fit in both mind and body. The individual's success and failure determination lie in the individual's practice to both physical and mental skills (http://recent-science.com).

Podrigalo et al. (2016) stated that mental toughness is considered a psychological way in which individuals react to a problematic situation and quickly recover. Mentally tough athletes suggested not only being highly resilient in stressful conditions and coping with the kind of stresses but flourishing in them.

Furthermore, mental toughness is the edge that helps a person remain consistent, confident, focused, and determined in high-pressure circumstances to attain their full potential. Mental toughness also allows a person to be well-mannered, ethical, courteous, helpful, pleasant, and warm. Mental toughness is the capacity to manage and conquer the body's and mind's natural, uncontrollable drives to achieve and sustain challenging goals and perform under hardship (http://recent-science.com). 


\section{DOI: $10.51386 / 25815946 /$ ijsms-v4i6p112}

Sports performance, whether in competition or practice, depends on the mental toughness skills of all athletes to reach peak performance. Coaches and performance specialists can leverage athlete and sports performance by defining the mental toughness triggers that lead to peak performance (Clough \& Strycharczyk, 2012).

Bull et al. (2005) and Mabandes et al. (2021) adopted competitiveness, uncompromising attitudes, different mindsets, and robust self-reliance as factors towards developing tough character in university students. Valiente et al. (2012) and Qualter et al. (2009) stated that their performance and confidence level might influence emotional intelligence in higher education students.

This study was conducted to give some knowledge or strategies to all the varsity athletes at Mindanao State University who wanted to perform well in sports. Also, it will reveal how varsity athletes respond or react to a situation at their performance level. This study will help them become mentally tough athletes. Research findings will help schools, universities, colleges, clubs, administrators, and athletic directors give adequate support and encourage the use of sport psychologists to strengthen mental toughness in athletes. This is very relevant based on the study results as athletes need to be mentally tough to perform well, avoid burnout, and maintain positive mental health.

\section{LITERATURE REVIEW}

\section{A. Mental Toughness: Is it Real?}

The mental toughness of athletes is an essential characteristic of a successful athlete; it has been acknowledged as one of the most fundamental traits underpinning performance and excellence in a sporting setting (Gucciardii et al., 2015). Mental toughness is of several tangible attributes. Suggested definitions include an individual's ability to persevere in the face of adversity and challenging situations; an ability to bounce back effectively from failure (Carr, 2010; Pagdato et el., 2021) an individual's ability to try their best every time and their ability to maintain concentration and confidence after a loss (Karageorghis \& Terry, 2010).

A study was carried out on the mental toughness of elite sports performers by Jones (2002). Twelve attributes vital for elite athletes to be mentally tough were identified. The three most important characteristics of a mentally tough elite sportsperson were passion, inspiration, self-belief, and motivation. All twelve attributes that are vital for mental toughness are equally reported by individual and team sports athletes. A growing body of research has identified the importance of several skills that can be coached and strengthened to make an individual more resilient in sport. Some of the psychological techniques which are most effective in improving mental toughness include positive thinking, mental imagery, changes of mindset, and strength-based approaches, which focus on reinforcing inherent strengths (Gordon 2012; Gucciardi \& Gordon, 2011).

Mental toughness techniques are becoming more commonly used to enhance performance, enjoy the sport, and improve general mental well-being. Harmison (2011) and Mabandes et al. (2021) suggests that for individuals to be resilient in achieving their peak performance, they need competent cognitive skills. This can be achieved with a sport psychologist working directly with a team or individual athletes.

According to solo athletes, team athletes have much stronger self-confidence, according to Zeng (2003). This finding suggests that mental toughness levels among team sport players would be greater because selfconfidence is a significant component of mental toughness, according to the "sport mental toughness questionnaire" (Sheard et al., 2009). Similarly, the research findings conducted on female athletes by Jalili et al. (2011) accord with those of Zeng (2003). According to this study, there were substantial disparities in levels of mental toughness between team athletes and individual athletes, with team players rating higher on levels of mental toughness.

Zeng (2003) reported significantly higher self-confidence levels in team athletes in comparison to individual athletes. This result gives us reason to believe that mental toughness levels will also be higher in team sports athletes. According to the "sport mental toughness questionnaire" (Sheard et al., 2009), self-confidence is a crucial element of mental toughness. Similarly, Jalili et al. (2011) result from a study carried out on female athletes agrees with Zeng's (2003) marks. This study revealed significant differences in levels of mental toughness between team athletes and individual athletes, with team athletes scoring higher in levels of mental toughness. This could be since team athletes are more aggressive, jealous, and proud than individual athletes. 


\section{DOI: $10.51386 / 25815946 /$ ijsms-v4i6p112}

This might be attributed to the competitive nature of the setting, where teammates compete daily; hence, ongoing competition necessitates superior mental toughness.

Furthermore, athletes who participate in team sports are impacted strongly by "team resilience." Team resilience is a psychosocial process that protects individuals from the possible adverse outcomes of stressors, pressure, and adversity. Individuals in a team combine their resources to react and cope effectively with adversity and challenges (Masten \& O'Dougherty Wright, 2010). Although several studies found significant differences in levels of mental toughness between team sports and individual sports, another study's results contradict these findings. Furthermore, Nicholls et al. (2009) discovered no statistically significant relationship between the team and individual sport athletes' levels of mental toughness.

Nicholls et al. (2009) found a significant association between mental toughness and years of sports experience when they investigated the influence of expertise on mental toughness. The results showed that athletes' levels of mental toughness increased in correlation with increasing age and a more substantial number of years of sporting experience. Also, as age and years of experience are likely closely related, it is suggested that biological and learning experience factors may impact this result.

\section{B. Identity As an Athlete}

Athletes' identity is a self-concept based on the degree of strength a person identifies with their muscular role; it develops from a self-schema about oneself (Griffith \& Johnson, 2002). Stambulova (1994) suggested that their sports careers engage one-third of an athlete's life. This shows how important sport is for an athlete's psychological well-being as it is central to their identity. It has never been distinguished whether individual sports athletes or team sports athletes have higher levels of athletic identity.

Athletic identity is paramount to athletes' success but can be potentially dangerous and lead to future problems. Individuals with powerful athletic identities can experience high levels of stress and anxiety during competitions, becoming overwhelming and traumatic for the athlete (Petrie et al., 2014). Also, the current literature suggests that high levels of athletic identity can harm the development of a broader personal identity, as their identity is firmly based on their muscular persona.

It's impossible to maintain persona all the time. It can be very problematic for athletes who are overly dependent on this role. Thus, if for any reason this role gets disrupted, for example, by a severe injury, athletes can, in turn, suffer from a lack of self-esteem, anxiety, and depression (Werthner \& Orlick, 1986). Although having excessively high levels of athletic identity can be problematic, research has found that high levels of athletic identity can also be beneficial. Having a solid athletic identity is associated with several psychological and physical health benefits, such as high levels of exercise, above-average levels of self-confidence, and increases in the quality of social relationships (Petitpas, 1978).

More so, the physical and mental health benefits of athletic identity, other researchers have discovered that high levels of athletic identity can help inhibit the use of recreational drugs, smoking, and consuming alcoholic beverages because of a strong connection and devotion to sport (Hudson, 2000).

\section{Years of Experience and Exposure in Sports Performance}

Years of experience and exposure to sports participation impact several fundamental variables for an individual to achieve success. Expert performance, for example, can only be obtained via years of expertise and exposure in their sport domain. This is due to the amount of practice carried out and the levels of knowledge gained through years of experience and exposure (Ericsson, 2006). Mental toughness is a vital characteristic for athletes' success and is affected by years of experience; Connaughton et al. (2008) outlined many underlying stages of mental toughness development that occur in the early, middle, and later years sport participation.

Results from the previous study suggested that each stage had a remarkable impact on the development of mental toughness. Results showed that during the early development stage of the sport, athletes first develop mental toughness through challenging and rewarding experiences in sport. In contrast, competition becomes 


\section{DOI: $\underline{10.51386 / 25815946 / i j s m s-v 4 i 6 p 112}$}

more intense in the middle years of the sport, and athletes must deal with many pressures and stressors in which greater resilience is required to adapt appropriately.

Lastly, in their later years of the sport, an athlete is at their most experienced, and mental toughness should be at its greatest due to the accumulation of competitive sport experiences that the athlete has participated in. Selfesteem is an underlying factor in the success, failure, and mental well-being of athletes. There has been a limited amount of research carried out on levels of self-esteem relative to age and years of experience in the sport. Several studies in psychology have investigated the effect age has on general levels of self-esteem. In a global survey of self-esteem across the life span, Robins et al. (2002) reported that individuals' levels of self-esteem in adulthood are steadily increasing in males between the ages of 18 and 69. As a result, there's a good chance that an athlete's self-esteem will improve as they become older and have more experience in the activity.

\section{METHODOLOGY AND METHODS}

This study utilized the descriptive-correlation research design with a questionnaire developed by Allan Goldberg (1998). The study's respondents were a total of 83 athletes, including 67 males and 16 females, representing the athletes of Mindanao State University in Marawi City. The data gathered was treated statistically using frequency count and percentage was utilized to measure the significant relationship between and among the variables.

\section{RESULTS AND DISCUSSION}

The following tables present the findings of results and discussions regarding the study.

Table 1. Reveals the frequency and percentage distribution of the respondents according to the level of participation and level of mental toughness. It can be gleaned from the table that the respondents were dominantly male with $67(80.72 \%)$, with the majority of males having a high level of the mental toughness of 40 (48.19\%), a national level of participation of 28 (33.73\%), and a high rank of 57 (68.67\%). Both males and females had a high mental toughness of 48 (57.83\%), with a national level of participation of $37(44.58 \%)$ and a rank final of $69(83.13 \%)$.

Table 1. Distribution of the Respondents According to rank, level of mental toughness and participation

\begin{tabular}{|l|c|c|c|c|c|c|}
\hline \multirow{2}{*}{ LEVEL OF MENTAL TOUGHNESS } & \multicolumn{2}{|c|}{ FEMALE } & \multicolumn{2}{c|}{ MALE } & \multicolumn{2}{|c|}{ SUMMARY } \\
\cline { 2 - 8 } & $\mathbf{f}$ & $\mathbf{\%}$ & $\mathbf{f}$ & $\mathbf{\%}$ & $\mathbf{f}$ & $\mathbf{\%}$ \\
\hline Very Low Mental Toughness & 0 & 0.00 & 0 & 0.00 & 0 & 0.00 \\
\hline Low Mental Toughness & 0 & 0.00 & 0 & 0.00 & 0 & 0.00 \\
\hline Average Mental Toughness & 7 & 8.43 & 25 & 30.12 & 32 & 38.55 \\
\hline High Mental Toughness & 8 & 9.64 & 40 & 48.19 & 48 & 57.83 \\
\hline Very High Mental Toughness & 1 & 1.20 & 2 & 2.41 & 3 & 3.61 \\
\hline Total & $\mathbf{1 6}$ & $\mathbf{1 9 . 2 8}$ & $\mathbf{6 7}$ & $\mathbf{8 0 . 7 2}$ & $\mathbf{8 3}$ & $\mathbf{1 0 0 . 0 0}$ \\
\hline LEVEL OF PARTICIPATION & & & & & & \\
\hline Local & 3 & 3.61 & 19 & 22.89 & 22 & 26.51 \\
\hline Regional & 4 & 4.82 & 20 & 24.10 & 24 & 28.92 \\
\hline National & 9 & 10.84 & 28 & 33.73 & 37 & 44.58 \\
\hline Total & $\mathbf{1 6}$ & $\mathbf{1 9 . 2 8}$ & $\mathbf{6 7}$ & $\mathbf{8 0 . 7 2}$ & $\mathbf{8 3}$ & $\mathbf{1 0 0 . 0 0}$ \\
\hline RANK & & & & & & \\
\hline Elimination & 0 & 0.00 & 2 & 2.41 & 2 & 2.41 \\
\hline Quarter Final & 0 & 0.00 & 2 & 2.41 & 2 & 2.41 \\
\hline Semi Final & 4 & 4.82 & 6 & 7.23 & 10 & 12.05 \\
\hline Final & 12 & 14.46 & 57 & 68.67 & 69 & 83.13 \\
\hline Total & $\mathbf{1 6}$ & $\mathbf{1 9 . 2 8}$ & $\mathbf{6 7}$ & $\mathbf{8 0 . 7 2}$ & $\mathbf{8 3}$ & $\mathbf{1 0 0 . 0 0}$ \\
\hline & & & & & \\
\end{tabular}


This means that all of the respondents, both males and females were highly possessing the desire to win, albeit in varying degrees The result implies that most of them have played in tournaments. More so, they showed better performance by reaching the semi-final and even the final round which is the highest level of competition.

\section{Mental Toughness and Level of Participation}

Table 2. shows the relationship between Mental Toughness and Level of Participation of the respondents. The Data revealed that majority of the respondents 48 out of $83(57.83 \%)$ who participated in all levels of sports competition have high level of mental toughness. While $21(25.30 \%)$ participate in National levels of sports competition.

Table 2. Relationship between Mental Toughness and Level of Participation

\begin{tabular}{|c|c|c|c|c|c|c|c|c|}
\hline \multirow{3}{*}{ MENTAL TOUGHNESS } & \multicolumn{6}{|c|}{ LEVEL OF PARTICIPATION } & \multirow{2}{*}{\multicolumn{2}{|c|}{ SUMMARY }} \\
\hline & \multicolumn{2}{|c|}{ LOCAL } & \multicolumn{2}{|c|}{ REGIONAL } & \multicolumn{2}{|c|}{ NATIONAL } & & \\
\hline & $\mathbf{F}$ & $\%$ & f & $\%$ & $\mathbf{f}$ & $\%$ & $\mathbf{f}$ & $\%$ \\
\hline Very Low Mental Toughness & 0 & 0.00 & 0 & 0.00 & 0 & 0.00 & 0 & 0.00 \\
\hline Low Mental Toughness & 0 & 0.00 & 0 & 0.00 & 0 & 0.00 & 0 & 0.00 \\
\hline Average Mental Toughness & 10 & 12.05 & 8 & 9.64 & 14 & 16.87 & 32 & 38.55 \\
\hline High Mental Toughness & 11 & 13.25 & 16 & 19.28 & 21 & 25.30 & 48 & 57.83 \\
\hline Very High Mental Toughness & 1 & 1.20 & 0 & 0.00 & 2 & 2.41 & 3 & 3.61 \\
\hline Total & 22 & 26.51 & 24 & 28.92 & 37 & 44.58 & 83 & 100.00 \\
\hline
\end{tabular}

As Jones (2002) had stated, mental toughness is the natural or developed psychological edge that enables one to generally cope better than his opponents with the many demands in competition and training, and specifically, be more consistent and better than the opponents, remaining determined, focused, confident, and in control under pressure.

Sports performance, whether in competition or in practice, depends on mental toughness skills of all athletes to reach peak performance. Coaches and performance specialist can leverage athlete and sports performance by defining the mental toughness triggers that lead to peak performance (Goldberg, 1998).

\section{Mental Toughness and Rank}

Table 3. presents the level of mental toughness in relationship with rank of the respondents which are presented below. It reveals the percentage of the respondents with high level of mental toughness reached the final round in the event that they play. A total frequency of $48(57.83 \%)$ of the respondents obtained high level of mental toughness, while respondents 26 (31.33\%) reached the final ranking in their various sports.

Table 3. Relationship between Mental Toughness and Rank of Participation

\begin{tabular}{|c|c|c|c|c|c|c|c|c|c|c|}
\hline \multirow{3}{*}{ MENTAL TOUGHNESS } & \multicolumn{8}{|c|}{ RANK } & \multirow{2}{*}{\multicolumn{2}{|c|}{ SUMMARY }} \\
\hline & \multicolumn{2}{|c|}{$\begin{array}{c}\text { ELIMINATI } \\
\text { ON }\end{array}$} & \multicolumn{2}{|c|}{$\begin{array}{l}\text { QUARTER } \\
\text { FINAL }\end{array}$} & \multicolumn{2}{|c|}{ SEMI FINAL } & \multicolumn{2}{|c|}{ FINAL } & & \\
\hline & $\mathbf{f}$ & $\%$ & $\mathbf{f}$ & $\%$ & f & $\%$ & $\mathbf{F}$ & $\%$ & $\mathbf{F}$ & $\%$ \\
\hline Very Low Mental Toughness & 0 & 0.00 & 0 & 0.00 & 0 & 0.00 & 0 & 0.00 & 0 & 0.00 \\
\hline Low Mental Toughness & 0 & 0.00 & 0 & 0.00 & 0 & 0.00 & 0 & 0.00 & 0 & 0.00 \\
\hline Average Mental Toughness & 2 & 2.41 & 0 & 0.00 & 4 & 4.82 & 26 & 31.33 & 32 & 38.55 \\
\hline High Mental Toughness & 0 & 0.00 & 2 & 2.41 & 6 & 7.23 & 40 & 48.19 & 48 & 57.83 \\
\hline $\begin{array}{l}\text { Very High Mental } \\
\text { Toughness }\end{array}$ & 0 & 0.00 & 0 & 0.00 & 0 & 0.00 & 3 & 3.61 & 3 & 3.61 \\
\hline Total & 2 & 2.41 & 2 & 2.41 & 10 & 12.05 & 69 & 83.13 & 83 & 100.00 \\
\hline
\end{tabular}


Players should have a higher level of mental toughness because they have experienced playing in championships (Lorentzen, 1981). Therefore, the coach holds the responsibility to inculcate the knowledge of psychology in the early stages (in schools) to strengthen the mental toughness of the players as to prepare them physically and mentally.

\section{Mental Toughness and Event}

Table 4 presents the frequency and percentage distribution of the respondents according to their respective sports event, grouped according to their level of mental toughness and its corresponding summary.

Table 4. Relationship between Mental Toughness and Sports event

\begin{tabular}{|c|c|c|c|c|c|c|c|c|}
\hline \multirow{3}{*}{ EVENT } & \multicolumn{6}{|c|}{ LEVEL OF MENTAL TOUGHNESS } & \multirow{2}{*}{\multicolumn{2}{|c|}{ SUMMARY }} \\
\hline & \multicolumn{2}{|c|}{$\begin{array}{c}\text { AVERAGE } \\
\text { MENTAL } \\
\text { TOUGHNESS }\end{array}$} & \multicolumn{2}{|c|}{$\begin{array}{c}\text { HIGH MENTAL } \\
\text { TOUGHNESS }\end{array}$} & \multicolumn{2}{|c|}{$\begin{array}{l}\text { VERY HIGH } \\
\text { MENTAL } \\
\text { TOUGHNESS }\end{array}$} & & \\
\hline & $\mathbf{F}$ & $\%$ & $\mathbf{f}$ & $\%$ & $\mathbf{f}$ & $\%$ & $\mathbf{f}$ & $\%$ \\
\hline Athletics & 6 & 7.23 & 5 & 6.02 & 0 & 0.00 & 11 & 13.25 \\
\hline Badminton & 1 & 1.20 & 6 & 7.23 & 1 & 1.20 & 8 & 9.64 \\
\hline Basketball & 8 & 9.64 & 4 & 4.82 & 0 & 0.00 & 12 & 14.46 \\
\hline Chess & 5 & 6.02 & 5 & 6.02 & 0 & 0.00 & 10 & 12.05 \\
\hline Sepak Takraw & 2 & 2.41 & 9 & 10.84 & 1 & 1.20 & 12 & 14.46 \\
\hline Soccer & 3 & 3.61 & 13 & 15.66 & 0 & 0.00 & 16 & 19.28 \\
\hline Volleyball & 4 & 4.82 & 5 & 6.02 & 0 & 0.00 & 9 & 10.84 \\
\hline Tennis & 3 & 3.61 & 1 & 1.20 & 1 & 1.20 & 5 & 6.02 \\
\hline Total & 32 & 38.55 & 48 & 57.83 & 3 & 3.61 & 83 & 100.00 \\
\hline
\end{tabular}

Most of the respondents have high mental toughness, 13 (15.66\%) from the soccer events, followed by Speak Takraw $12(14.46 \%)$, while the level of the mental toughness of the respondents across all the events ranges from average to very high. This study found that team athlete rated the importance of their role as an athlete, social relationships, and personal attributes more highly than individual athletes. These findings complement the current study results, as the above variables are positively related to the formation of athletic identity. We can infer that the theory of social identity may explain significantly higher levels of athletic identity in team athletes. This theory suggests that being part of a particular social team strongly impacts a person's identity and who they think they are (Hogg, 2006). As team athletes have shared goals and attributes, something that separates them from individual athletes whose goals are primarily concentrated on themselves, less social interaction and bonding is likely to occur between individual athletes. Therefore, they won't form as much of a relationship with other athletes, which affects their athletic identity. On the other hand, team members share team goals, wins, and losses, and succeeding is contingent on teamwork within the team, and because of this, it is more likely to strengthen stronger bonds between team athletes (Tajfel \& Turner, 2004).

\section{Mental Toughness and Age}

Results of the relationship between mental toughness and age of respondents show that the respondents' 20 years had $19(22.89 \%)$ with a high mental toughness of $11(13.25 \%)$, as shown in the table below. This indicates that the high level of mental toughness of the respondents at their age is visible, with 48 (57.83\%). As a result, neither older nor younger ages are used to determine if a player is mentally challenging, but rather the aptitude and capability to deal with challenges, pressure, stresses, and hurdles while playing the game. Furthermore, Robins et al. (2002) explain that mental toughness is steadily increasing in adulthood between 18 and 69 because the most experienced athletes are likely to be older. This may explain why the highest levels of mental toughness are found in the most experienced group. This is corroborated by the findings of Nicholls et al. (2009), who discovered that mental toughness increased considerably with respondents' age. 
Table 5. Relationship between Mental Toughness and Age of the respondents

\begin{tabular}{|c|c|c|c|c|c|c|c|c|}
\hline \multirow{3}{*}{ AGE } & \multicolumn{8}{|c|}{ LEVEL OF MENTAL TOUGHNESS } \\
\hline & \multicolumn{2}{|c|}{$\begin{array}{c}\text { AVERAGE } \\
\text { MENTAL } \\
\text { TOUGHNESS }\end{array}$} & \multicolumn{2}{|c|}{$\begin{array}{l}\text { HIGH MENTAL } \\
\text { TOUGHNESS }\end{array}$} & \multicolumn{2}{|c|}{$\begin{array}{c}\text { VERY HIGH } \\
\text { MENTAL } \\
\text { TOUGHNESS }\end{array}$} & \multicolumn{2}{|c|}{ SUMMARY } \\
\hline & $\mathbf{f}$ & $\%$ & $\mathbf{f}$ & $\%$ & $\mathbf{F}$ & $\%$ & $\mathbf{f}$ & $\%$ \\
\hline 16 & 3 & 3.61 & 3 & 3.61 & 1 & 1.20 & 7 & 8.43 \\
\hline 17 & 2 & 2.41 & 5 & 6.02 & 0 & 0.00 & 7 & 8.43 \\
\hline 18 & 6 & 7.23 & 7 & 8.43 & 0 & 0.00 & 13 & 15.66 \\
\hline 19 & 7 & 8.43 & 10 & 12.05 & 1 & 1.20 & 18 & 21.69 \\
\hline 20 & 8 & 9.64 & 11 & 13.25 & 0 & 0.00 & 19 & 22.89 \\
\hline 21 & 2 & 2.41 & 6 & 7.23 & 0 & 0.00 & 8 & 9.64 \\
\hline 22 & 1 & 1.20 & 3 & 3.61 & 0 & 0.00 & 4 & 4.82 \\
\hline 23 & 2 & 2.41 & 2 & 2.41 & 1 & 1.20 & 5 & 6.02 \\
\hline 24 & 1 & 1.20 & 1 & 1.20 & 0 & 0.00 & 2 & 2.41 \\
\hline Total & 32 & 38.55 & 48 & 57.83 & 3 & 3.61 & 83 & 100.00 \\
\hline
\end{tabular}

\section{Mental Toughness and Playing Experience}

Relationship between level of mental toughness and years of playing experience of the respondents are determined and presented in Table 6, which shows the majority of the respondents have 5 years and above playing experience with $64(77.11 \%)$, also had 36 (43.37\%) of high mental toughness.

Table 6. Relationship between Mental Toughness and Playing Experience

\begin{tabular}{|c|c|c|c|c|c|c|c|c|}
\hline \multirow{3}{*}{$\begin{array}{c}\text { PLAYING } \\
\text { EXPERIENCE }\end{array}$} & \multicolumn{6}{|c|}{ LEVEL OF MENTAL TOUGHNESS } & & \\
\hline & \multicolumn{2}{|c|}{$\begin{array}{c}\text { AVERAGE } \\
\text { MENTAL } \\
\text { TOUGHNESS }\end{array}$} & \multicolumn{2}{|c|}{$\begin{array}{c}\text { HIGH } \\
\text { MENTAL } \\
\text { TOUGHNESS }\end{array}$} & \multicolumn{2}{|c|}{$\begin{array}{l}\text { VERY HIGH } \\
\text { MENTAL } \\
\text { TOUGHNESS }\end{array}$} & \multicolumn{2}{|c|}{ SUMMARY } \\
\hline & $\mathbf{F}$ & $\%$ & f & $\%$ & $\mathbf{F}$ & $\%$ & $\mathbf{F}$ & $\%$ \\
\hline $\begin{array}{l}\text { Less Than } \\
1 \text { Year }\end{array}$ & 1 & 1.20 & 1 & 1.20 & 0 & 0.00 & 2 & 2.41 \\
\hline 1 Year & 4 & 4.82 & 3 & 3.61 & 0 & 0.00 & 7 & 8.43 \\
\hline 2 Years & 0 & 0.00 & 1 & 1.20 & 0 & 0.00 & 1 & 1.20 \\
\hline 3 Years & 0 & 0.00 & 2 & 2.41 & 0 & 0.00 & 2 & 2.41 \\
\hline 4 Years & 2 & 2.41 & 5 & 6.02 & 0 & 0.00 & 7 & 8.43 \\
\hline $\begin{array}{l}5 \text { Years and } \\
\text { Above }\end{array}$ & 25 & 30.12 & 36 & 43.37 & 3 & 3.61 & 64 & 77.11 \\
\hline Total & 32 & 38.55 & 48 & 57.83 & 3 & 3.61 & 83 & 100.00 \\
\hline
\end{tabular}

Support by Connaughton et al. (2008), Mental toughness is a vital characteristic for athletes' success and is affected by playing and years of experience; outlined many underlying stages of mental toughness development that occur in the early, middle, and later years sport participation. Results from the previous study suggested that each stage had a remarkable impact on the development of mental toughness. Results showed that during the early development stage of the sport, athletes first develop mental toughness through challenging and rewarding experiences in sport. In contrast, competition becomes more intense in the middle years of the sport, and athletes must deal with many pressures and stressors in which greater resilience is required to adapt appropriately.

\section{Level of Participation and Event}

Data on the level of participation according to the event of the respondents is presented in Table 7 . It reveals that the respondents participate well in National levels $10(12.05 \%)$, While soccer had the most respondents' events that they participated in $16(19.28 \%)$. 


\section{DOI: $10.51386 / 25815946 /$ ijsms-v4i6p112}

Volume: 4 Issue: 6

November to December 2021

https://www.ijsmsjournal.org

Table 7. Relationship between Level of Participation and Event

\begin{tabular}{|c|c|c|c|c|c|c|c|c|}
\hline \multirow{3}{*}{ EVENT } & \multicolumn{6}{|c|}{ LEVEL OF PARTICIPATION } & & \\
\hline & \multicolumn{2}{|c|}{ LOCAL } & \multicolumn{2}{|c|}{ REGIONAL } & \multicolumn{2}{|c|}{ NATIONAL } & \multicolumn{2}{|c|}{ SUMMARY } \\
\hline & $\mathbf{f}$ & $\%$ & $\mathbf{f}$ & $\%$ & $\mathbf{f}$ & $\%$ & $\mathbf{f}$ & $\%$ \\
\hline Athletics & 4 & 4.82 & 2 & 2.41 & 5 & 6.02 & 11 & 13.25 \\
\hline Badminton & 1 & 1.20 & 1 & 1.20 & 6 & 7.23 & 8 & 9.64 \\
\hline Basketball & 6 & 7.23 & 2 & 2.41 & 4 & 4.82 & 12 & 14.46 \\
\hline Chess & 2 & 2.41 & 3 & 3.61 & 5 & 6.02 & 10 & 12.05 \\
\hline Sepak Takraw & 1 & 1.20 & 6 & 7.23 & 5 & 6.02 & 12 & 14.46 \\
\hline Soccer & 3 & 3.61 & 3 & 3.61 & 10 & 12.05 & 16 & 19.28 \\
\hline Volleyball & 3 & 3.61 & 5 & 6.02 & 1 & 1.20 & 9 & 10.84 \\
\hline Tennis & 2 & 2.41 & 2 & 2.41 & 1 & 1.20 & 5 & 6.02 \\
\hline Total & 22 & 26.51 & 24 & 28.92 & 37 & 44.58 & 83 & 100.00 \\
\hline
\end{tabular}

This could be attributed to the fact that soccer nowadays gained its popularity and given opportunity to more participants than any even in sports. In the University and the community, these sports activities are engaging in grassroots.

\section{Level of Participation and Age} Table 8

Relationship between level of participation and age of the respondents are determined and presented in

Table 8, Relationship between Level of Participation and Age of the respondents.

\begin{tabular}{|c|c|c|c|c|c|c|c|c|}
\hline \multirow{3}{*}{ AGE } & \multicolumn{6}{|c|}{ LEVEL OF PARTICIPATION } & \multirow{2}{*}{\multicolumn{2}{|c|}{ SUMMARY }} \\
\hline & \multicolumn{2}{|c|}{ LOCAL } & \multicolumn{2}{|c|}{ REGIONAL } & \multicolumn{2}{|c|}{ NATIONAL } & & \\
\hline & $\mathbf{f}$ & & $\mathbf{f}$ & $\%$ & $\mathbf{f}$ & $\%$ & $\mathbf{f}$ & $\%$ \\
\hline 16 & 3 & 3.61 & 4 & 4.82 & 0 & 0.00 & 7 & 8.43 \\
\hline 17 & 3 & 3.61 & 2 & 2.41 & 2 & 2.41 & 7 & 8.43 \\
\hline 18 & 6 & 7.23 & 3 & 3.61 & 4 & 4.82 & 13 & 15.66 \\
\hline 19 & 5 & 6.02 & 6 & 7.23 & 7 & 8.43 & 18 & 21.69 \\
\hline 20 & 1 & 1.20 & 7 & 8.43 & 11 & 13.25 & 19 & 22.89 \\
\hline 21 & 2 & 2.41 & 0 & 0.00 & 6 & 7.23 & 8 & 9.64 \\
\hline 22 & 0 & 0.00 & 2 & 2.41 & 2 & 2.41 & 4 & 4.82 \\
\hline 23 & 2 & 2.41 & 0 & 0.00 & 3 & 3.61 & 5 & 6.02 \\
\hline 24 & 0 & 0.00 & 0 & 0.00 & 2 & 2.41 & 2 & 2.41 \\
\hline Total & 22 & 26.51 & 24 & 28.92 & 37 & 44.58 & 83 & 100.00 \\
\hline
\end{tabular}

The table shared most of the respondents in the age range of 20 (22.9\%) with a total frequency of 19. The result shows that the age ranges from 18 to 20 indicate an excellent performance concerning the highest level of competition they participated in. It implies that the athlete's highest level of competition is determined by age due to its strength; only a few respondents (19 out of 83) have less than five years of playing experience. According to Ómarsson (2013) findings, the similarity in these results may have something to do with the difference in age groups within the samples, as the current study uses a variety of ages ranging from 16 to 24 years same as compared to Ómarsson (2013) who had a piece of solely high school athletes aged 17. Although it hypothesized that team athletes with such age would score higher on their level of performance both in strength and ability levels because of their age, the present study found no difference. This shows that age determines respondents' level of participation at the local, region, and national levels. The better younger respondents may have better strength and determination in their events during tournaments. 


\section{Level of Participation and Playing Experience}

Table 9 show the relationship between level of participation and years of playing experience of the respondents. Table shows that majority or $77.11 \%$ of the respondents with a frequency of 64 have 5 years or more playing experience. In terms of participation, majority of the respondents with 5 years or more years of playing experience (64 out of 83) have participated in all levels of competition. Among these players, 30 respondents $(36.14 \%)$ played in the national level.

Table 9. Relationship between Level of Participation and Playing Experience

\begin{tabular}{|c|c|c|c|c|c|c|c|c|}
\hline \multirow{3}{*}{$\begin{array}{c}\text { PLAYING } \\
\text { EXPERIENCE } \\
\text { (years) }\end{array}$} & \multicolumn{6}{|c|}{ LEVEL OF PARTICIPATION } & \multirow{2}{*}{\multicolumn{2}{|c|}{ SUMMARY }} \\
\hline & \multicolumn{2}{|c|}{ LOCAL } & \multicolumn{2}{|c|}{ REGIONAL } & \multicolumn{2}{|c|}{ NATIONAL } & & \\
\hline & $\mathbf{F}$ & $\%$ & $\mathbf{f}$ & $\%$ & $\mathbf{f}$ & $\%$ & $\mathbf{F}$ & $\%$ \\
\hline Less than $1 \mathrm{yr}$ & 2 & 2.41 & 0 & 0.00 & 0 & 0.00 & 2 & 2.41 \\
\hline $1 \mathrm{yr}$ & 5 & 6.02 & 0 & 0.00 & 2 & 2.41 & 7 & 8.43 \\
\hline $2 \mathrm{yrs}$ & 0 & 0.00 & 1 & 1.20 & 0 & 0.00 & 1 & 1.20 \\
\hline 3 yrs & 0 & 0.00 & 1 & 1.20 & 1 & 1.20 & 2 & 2.41 \\
\hline 4 yrs & 2 & 2.41 & 1 & 1.20 & 4 & 4.82 & 7 & 8.43 \\
\hline 5 yrs and above & 13 & 15.66 & 21 & 25.30 & 30 & 36.14 & 64 & 77.11 \\
\hline Total & 22 & 26.51 & 24 & 28.92 & 37 & 44.58 & 83 & 100.00 \\
\hline
\end{tabular}

The level of participation and playing experience of athletes will help their performance in various sports events. It seemed to be related to the creativity of the athletes. The total number of years used in playing will help athletes be exposed to and involved in mental toughness. Years of experience and competitive experience are unrelated to all measures of creativity. It has been proposed that the adaptive outcomes of sport participation can be grouped into the three P's of performance (the development of sport expertise), participation (engagement in sport or physical activity throughout life), and personal development (healthy psychological, social, and emotional development Côté et al., 2016). However, sports participation alone does not seem to be sufficient to explain the attainment of these long-term adaptive outcomes of playing experiences, as sports participation can also lead to maladaptive results, such as burnout, stress, and dropout (Crane \& Temple, 2015). Thus, long-term goals of achieving higher skills in sport often come at the cost of immediate gratification and enjoyment (Côté \& Abernethy, 2012).

\section{CONCLUSIONS AND RECOMMENDATION}

\section{A. Conclusion}

In conclusion, this study revealed that most respondents were males within 20 years of age. They were very mentally tough in participating at both the national and regional levels. During this period, they reach the final stages of the various tournaments that they experience. It was noticed that most respondents have been participating for five years or more in team sports like soccer and sepak takraw, which gives them the confidence to build teamwork among their peers. Also, the level of participation is reflected in their playing experience, as they have participated in various events for years. Surprisingly, years of experience did not affect mental toughness, which may be due to mental toughness being a somewhat fixed biological characteristic.

\section{B. Recommendations}

The researchers recommended the following: (1) The Department of Athletics should regularly participate in a higher level of competition like open national competitions for exposure and experience of university varsity athletes. (2) Parents should encourage their children to engage in sports starting at an early age to enhance their skills and develop their attitudes and behaviors; a possible higher level of competition must have participated. (3) The Department of Athletics should emphasize training and participation among MSU varsity in different competitions or tournaments. This improves their skills, manages competitive stress, and enhances their mental capacity to handle those pressures, stressors, and problems during the competition, which may enhance their performance. (4) Encourage more participation of the MSU varsity athletes, particularly beginners, regardless of age, gender, and skills status. (5) Conduct further studies using more respondents and other psychological components. 


\section{DOI: $\underline{10.51386 / 25815946 / \mathrm{ijsms}-\mathrm{v} 4 \mathrm{i} 6 \mathrm{p} 112}$}

Volume: 4 Issue: 6

November to December 2021

https://www.ijsmsjournal.org

\section{ACKNOWLEDGMENT}

This research would not have been possible without the support of our dear College Dean, Dr. Hendely A. Adlawan; her enthusiasm, knowledge, and exacting attention to detail have been an inspiration and kept our work on track from the first encountered. Our colleagues at the College of SPEAR Mindanao State University (Main), Marawi, Philippines. We were also grateful for the insightful comments offered by the anonymous peer reviewers at IJSMS Journal. The unselfishness and creativity of one and all have improved this research in innumerable ways and saved us from many errors, those that inevitably remain our entire responsibility. God bless you all.

Ethical Approval: Approval from CSPEAR Ethics Committee was obtained to conduct the study.

Conflicts of interest: The authors declare no conflict of interest.

OrCID IDs: 0000-0002-3444-4713

\section{REFERENCES}

[1] American Psychological Association. (2012). Sport, Exercise and Performance Psychology. http://www.apa.org/pubs/journals/spy/index.aspx.

[2] Bull, S. J., Shambrook, C. J., James, W. \& Brooks, J. E. (2005). Towards an understanding of mental toughness in elite English cricketers. Journal of applied sport psychology,17(3),209-227. https://doi.org/10.1080/10413200591010085 (Accessed Nov 22, 2021).

[3] Carr, D. (2010). Winning through mental toughness: The key to success in sports and in life. United States: Xulon Press.

[4] Connaughton, D., Wadey, R., Hanton, S., \& Jones, G. (2008). The development and maintenance of mental toughness: Perceptions of elite performers. Journal of Sports Sciences, 26(1), 83-95

[5] Côté, J. \& Abernethy, B. (2012). A developmental approach to sport expertise. In Murphy, S. (Ed.), The Oxford handbook of sport and performance psychology. 435-447. Oxford University Press.

[6] Côté, J., Turnnidge, J.\& Vierimaa, M. (2016). A personal assets approach to youth sport. In K. Green \& A. Smith (Eds), Routledge handbook of youth sport (pp. 243-255). Routledge.

[7] Cox, R. H. ((2002). Sport psychology: concepts and applications. (4th ed). Boston MA: McGraw-Hill.

[8] Clough, P. \& Strycharczyk, D. (2012). Developing mental toughness improving performance, wellbeing and positive

[9] behaviour in others. Philadelphia, PA: Kogan Page Limited.

[10] Crane, J., \& Temple, V. (2015). A systematic review of dropout from organized sport among children and youth. European Physical Education Review, 21(1), 114-131.

[11] Ericsson, K. A. (2006). The influence of experience and deliberate practice on the development of superior expert performance. The Cambridge handbook of expertise and expert performance, 683-703.

[12] Goldberg, A. S. (1998). Sports slump busting: 10 steps to mental toughness and peak performance. Champaign, IL: Human Kinetics.

[13] Gordon, S. (2012). Strengths-based approaches to developing mental toughness: Team and individual. International Coaching Psychology Review, 7(2), 210-222.

[14] Griffith, K. A., \& Johnson, K. A. (2002). Athletic identity and life roles of Division I and Division III collegiate athletes. Journal of Undergraduate Research, 5, 225-231.

[15] Gucciardi, D. F., \& Gordon, S. (2011). Mental toughness in sport: Developments in research and theory. London: Routledge.

[16] Harmison, R. J. (2011). Peak performance in sport: Identifying ideal performance states and developing athletes' psychological skills.

[17] Hogg, M. A. (2006). Social identity theory. Contemporary social psychological theories, 13, 111-1369.

[18] Hudson, A. (2000). Effects of athletic involvement on the social life: A study of 68 track and field athletes. Unpublished manuscript.

[19] Jalili, F., Hosseini, A., \& Salehian, H. (2011). Comparison of personality dimensions, mental toughness, and social skills of female students' athletes (team-individual) and nonathletes. Annals of Biological Research, 2(6), 554-560.

[20] Jones, G. (2002). What is this thing called mental toughness? An investigation of elite sport performers. Journal of applied sport psychology,14(3), 205-218. 


\section{DOI: $\underline{10.51386 / 25815946 / \mathrm{ijsms}-v 4 \mathrm{i} 6 \mathrm{p} 112}$}

Volume: 4 Issue: 6

November to December 2021

https://www.ijsmsjournal.org

[21] Karageorghis, I.C. \& Terry, C.P. (2016). Inside Sport Psychology.1 - 44. http://dx.doi.org/10.5040/9781492595564.

[22] Manbades, L.L., Fadare, A.S. \& Adlawan, A.H. (2021). Karate-do Athletes' Reactions to Aggression and Motivation during Fit and Well Zone Tournament Performance. International Journal of Science and Management Studies (IJSMS).4(3), 211219.doi.10.51386/25815946/ijsms-v4i3p119.

[23] Nicholls, A. R., Polman, R. C., Levy, A. R., \& Backhouse, S. H. (2009). Mental toughness in sport: Achievement level, gender, age, experience, and sport type differences. Personality and Individual Differences, 47(1), 73-75.

[24] Ómarsson, B. P. (2013). Effects of sport participation on adolescent self-esteem and body image: differences in gender and types of sports explored.

[25] Pagdato, V. J., Gallardo, M., Fadare, A.S \& Adlawan, A.H. (2021). Motivation and Mental Toughness among Table Tennis Athletes: Achievement in Sports Performance. International Journal of Science and Management studies. (IJSMS), 4(3), 162-170.

[26] Petitpas, A. J. (1978). Identity foreclosure: A unique challenge. Personnel and Guidance Journal, 56, 558-561.

[27] Petrie, Trent A., Jay Deiters. \& Robert, J. H. (2014). "Mental toughness, social support, and athletic identity: Moderators of the life stress-injury relationship in collegiate football players." Sport, Exercise, And Performance Psychology 3(1), 13-27.

[28] Podrigalo, L., Iermakov, S., Rovnaya, O., Zukow, W. \& Nosko. M. (2016). Peculiar features between the studied indicators of the dynamic and interconnections of mental workability of students. Journal of Physical Education and Sport,16(4), 12111218.doi:10.7752/jpes.2016.04193.

[29] Qualter, P., Whiteley, H., Morley, A., \& Dudiak, H. (2009). The role of emotional intelligence in the decision to persist with academic studies in HE. Research in Post Compulsory Education,14(3), 219 -231. https://doi.org/10.1080/13596740903139255.

[30] Robins, R. W., Trzesniewski, K. H., Tracy, J. L., Gosling, S. D. \& Potter, J. (2002). Global self-esteem across the life span. Psychology and aging, 17(3), 423.

[31] Sheard, M., Golby, J., \& van Wersch, A. (2009). Progress toward construct validation of the Sports Mental Toughness Questionnaire (SMTQ). European Journal of Psychological Assessment, 25(3), 186-193.

[32] Stambulova, N. B. (1994). Developmental sports career investigations in Russia: A postperestroika analysis. The Sport Psychologist, $8,221-237$.

[33] Tajfel, H., \& Turner, J. C. (2004). The Social Identity Theory of Intergroup Behaviour. In J. T. Jost, J. Sidanius, J. T. Jost, J. Sidanius (Eds.), Political psychology: Key readings (pp. 276-293). New York, NY, US: Psychology Press.

[34] Valiente, C., Swanson, J., \& Eisenberg, N. (2012). Linking students' emotions and academic achievement: When and why emotions matter. Child development perspectives, 6(2), 129-135. https://doi.org/10.1111/j.1750-8606.2011.00192.x. (Accessed Nov 22, 2021).

[35] Werthner, P.M. \& Orlick, T. (1986). Retirement experiences of successful Olympic athletes. International Journal of Sport Psychology, 17, 337-363.

[36] Williams, J. M. (2001). Applied sport psychology: Personal growth to peak performance. New York: McGraw-Hill.

[37] Zeng, H. Z. (2003). The Differences between Anxiety and Self-Confidence between Team and Individual Sports College Varsity Athletes. International Sports Journal, 7(1), 28. 